\title{
Estrutura do dossel em pastagens de capim-marandu submetidas a quatro ofertas de lâminas foliares
}

\author{
Luís Armando Zago Machado(1), Amoacy Carvalho Fabrício(1), Paulo Giovani Gall de Assis ${ }^{(1)}$ \\ e Gerzy Ernesto Maraschin (2)
}

\begin{abstract}
(1)Embrapa Agropecuária Oeste, BR 163, Km 253, Caixa Postal 661, CEP 79804-970 Dourados, MS. E-mail: zago@cpao.embrapa.br, amoacy@cpao.embrapa.br, giovani@cpao.embrapa.br (2)Fundação Estadual de Pesquisa Agropecuária, Rua Gonçalves Dias, no 570, Bairro Menino Deus, CEP 90130-060 Porto Alegre, RS. E-mail: gerzy@terra.com.br
\end{abstract}

\begin{abstract}
Resumo - O objetivo deste trabalho foi avaliar a estrutura do dossel, em pastagens de Brachiaria brizantha cultivar Marandu submetidas a quatro ofertas de lâminas foliares. A espécie forrageira foi semeada em janeiro de 2001, na área experimental da Embrapa Agropecuária Oeste, Dourados, MS, e as pastagens foram submetidas às ofertas de forragem de 4, 8, 12 e 16\% (quilogramas de lâminas foliares verdes por $100 \mathrm{~kg}$ de peso vivo por dia). $\mathrm{O}$ delineamento experimental foi o de blocos ao acaso, com duas repetições. As unidades experimentais foram avaliadas mensalmente, de outubro de 2002 a maio de 2003, de outubro de 2003 a junho de 2004 e de novembro de 2004 a junho de 2005. As ofertas de forragem foram mantidas sob regime de lotação contínua. A massa de lâminas foliares verdes e a altura do dossel apresentaram aumento linear com o aumento das ofertas de lâminas. As regressões oferta de lâminas foliares, taxa de acúmulo de lâminas foliares e matéria seca de raízes não foram significativas. A massa de lâminas foliares e altura do dossel aumentam com a oferta.
\end{abstract}

Termos para indexação: Brachiaria brizantha, altura do dossel, matéria seca de raízes, matéria seca de folhas, taxa de acúmulo.

\section{Sward structure of Marandu palisade grass pastures at four allowances of leaf blade}

\begin{abstract}
The objective of this work was to evaluate the sward structure of Brachiaria brizantha cultivar Marandu pastures in response to leaf blade allowance. The forage grass was sown in January 2001, at Embrapa Agropecuária Oeste, Dourados, MS, Brazil and the allowances were 4, 8, 12 and 16\% (kilograms of leaf blade per $100 \mathrm{~kg}$ of live weight per day). The experimental design was complete randomized blocks, with two replicates. The pasture was monthly evaluated during from October 2002 to May 2003, October 2003 to June 2004 and November 2004 to June 2005. The allowances were kept constant with put-and-take animals and continuous stocking grazing. The leaf blade mass and sward height increased linearly as a function of leaf blade allowance. The leaf blade accumulation rate and the root dry matter did not respond to the increase of allowance. The leaf blade mass and sward height vary with leaf blade allowance.
\end{abstract}

Index terms: Brachiaria brizantha, sward height, root dry matter, leaf dry mass, accumulation rate.

\section{Introdução}

Apesar de a Região do Cerrado, no Brasil Central, ser responsável por mais da metade da produção nacional de carne bovina, estima-se que $80 \%$ das pastagens nessa região encontram-se em algum estágio de degradação (Barcellos, 1996). Este processo está associado à ausência de cobertura do solo, redução do sistema radicular e compactação do solo (Muller et al., 2001).

Em contribuição à degradação das pastagens na Região do Cerrado, ocorrem diversos problemas de manejo que vão desde a má formação da pastagem, cultivo de espécies não adaptadas, ataque de pragas, doenças e invasão de plantas daninhas (Peron \& Evangelista, 2004). O manejo do pastejo e a falta de reposição de nutrientes minerais, entretanto, são as principais causas do processo de degradação das pastagens.

O superpastejo se manifesta como resultado do uso de taxas de lotação superiores à capacidade de suporte da pastagem. Em levantamento realizado por Costa (2000), na Região Central de Mato Grosso do Sul, constatou-se que o superpastejo é uma prática 
generalizada, e $88 \%$ dos técnicos relatam que ele ocorre em mais de $60 \%$ das fazendas. As desfolhas freqüentes e intensas comprometem a capacidade de rebrotação da planta forrageira e, conseqüentemente, a baixa disponibilidade de forragem limita o desempenho dos animais (Machado \& Kichel, 2004). Uma medida de baixo investimento, que permite aumentar a renda líquida do produtor, é o ajuste da taxa de lotação aos limites do ecossistema. Esse ajuste pode ser feito, tomando-se como referência atributos da estrutura do dossel como altura e massa de forragem ou, ainda, a oferta de forragem.

Para o capim-mombaça, sob lotação intermitente, são recomendadas alturas de pré e pós-pastejo de 90 e $30 \mathrm{~cm}$, respectivamente (Carnevalli, 2003). Para a cultivar Tanzânia, as alturas de manejo recomendadas são 70 e $25 \mathrm{~cm}$, respectivamente para pré e pós-pastejo (Barbosa, 2004). A manutenção da massa de forragem é outra forma de ajuste da taxa de lotação. Dos componentes da planta forrageira, a fração lâmina foliar apresenta o melhor valor nutritivo e representa mais de $80 \%$ da forragem consumida (Forbes \& Hodgson, 1985). Como as lâminas foliares possuem melhor valor nutritivo do que colmos e bainhas foliares, o manejo do pastejo deve ser direcionado para maior contribuição desse componente (Cano et al., 2004). $\mathrm{O}$ ajuste da taxa de lotação à altura do dossel ou à massa de forragem está sujeito a erros, já que frações pouco consumidas pelos animais, como os colmos e a matéria morta, variam ao longo do tempo. Com isto, numa mesma altura do dossel ou massa de forragem pode haver diferentes massas de lâminas foliares.

Em pastagens de cultivares do gênero Panicum, em regime de lotação contínua, Euclides \& Euclides Filho (2001) observaram ganhos crescentes de peso por animal até a massa de forragem de $900 \mathrm{~kg} \mathrm{ha}^{-1}$, considerados apenas os componentes verdes da planta forrageira. Em lotação rotacionada, Carnevalli (2003) observou para o capim-mombaça a massa de forragem, no pré-pastejo, de aproximadamente $5.000 \mathrm{~kg} \mathrm{ha}^{-1} \mathrm{e}$, em pós-pastejo, próximo de $2.000 \mathrm{~kg} \mathrm{ha}^{-1}$. Para o capim-elefante anão cultivar Mott, sob lotação contínua, Almeida et al. (2000b) concluíram que a massa adequada de lâminas foliares, ao ganho máximo por animal, foi de $2.200 \mathrm{~kg} \mathrm{ha}^{-1}$.

A determinação da quantidade de lâminas foliares possibilita o cálculo da taxa de lotação, com base na oferta de lâminas foliares. O consumo de forragem é maximizado, quando o nível de oferta de forragem é de três a quatro vezes a capacidade de ingestão dos animais
(Hodgson, 1984). A oferta de lâminas foliares verdes é o componente do manejo que permite predizer com segurança o desempenho animal, por integrar a massa de lâminas foliares com a taxa de lotação (Sollenberger et al., 2005). O método que associa oferta de forragem com taxa de lotação variável foi discutido por Mott \& Lucas (1952), em condição de clima temperado e, por Maraschin \& Mott (1989), para espécies forrageiras de clima tropical. É indispensável trabalhar com a fração lâmina foliar em espécies tropicais, em razão do grande acúmulo de colmos e material senescente. Para o capimelefante anão 'Mott', sob lotação contínua, Almeida et al. (2000a, 2000b) observaram que a oferta de lâminas foliares de $11,3 \%$ do peso vivo permitiu máximo ganho por animal e assegurou condição de sustentabilidade da pastagem.

A Brachiaria brizantha (Hochst. ex A. Rich) Stapf cultivar Marandu foi lançada pela Embrapa em 1984 e por apresentar boa produtividade e qualidade da forragem, rápido estabelecimento, boa cobertura de solos e capacidade de competição com invasoras, passou a ser uma das principais espécies forrageiras utilizadas na Região Centro-Oeste e no Brasil, onde ocupa uma área de cerca de 70 milhões de hectares (Embrapa, 2007). Apesar da importância desta cultivar, não existem trabalhos relacionados à oferta de forragem.

O objetivo deste trabalho foi avaliar a estrutura do dossel, em pastagens de Brachiaria brizantha cultivar Marandu submetidas a quatro ofertas de lâminas foliares.

\section{Material e Métodos}

O experimento foi conduzido na Embrapa Agropecuária Oeste, em Dourados, MS (altitude de $430 \mathrm{~m}, 22^{\circ} 14^{\prime} \mathrm{S}$ e $54^{\circ} 49^{\prime} \mathrm{W}$ ). A espécie Brachiaria brizantha cultivar Marandu foi semeada em fevereiro de 2001, num Latossolo Vermelho distroférrico típico, mantido há mais de 20 anos com culturas anuais, principalmente soja. Ao término do experimento, a análise química do solo apresentou: $\mathrm{pH} \mathrm{CaCl}_{2}, 4,7 ; \mathrm{Al}$, $0,28 \mathrm{cmol}_{\mathrm{c}} \mathrm{dm}^{-3} ; \mathrm{Ca}, 3,8 \mathrm{cmol}_{\mathrm{c}} \mathrm{dm}^{-3} ; \mathrm{Mg}, 1,7 \mathrm{cmol}_{\mathrm{c}} \mathrm{dm}^{-3}$; $\mathrm{K}, 0,6 \mathrm{cmol}_{\mathrm{c}} \mathrm{dm}^{-3}$; $\mathrm{P}, 6,5 \mathrm{mg} \mathrm{dm}^{-3}$; CTC efetiva, $6,4 \mathrm{cmol}_{\mathrm{c}} \mathrm{dm}^{-3} ; \mathrm{V}, 46,2 \%$ e MO, $31,8 \mathrm{~g} \mathrm{~kg}^{-1}$.

O delineamento experimental utilizado foi o de blocos ao acaso, com duas repetições. De janeiro a julho de 2002, a pastagem foi submetida às ofertas planejadas de lâminas foliares de 5, 8, 11 e 14\% (quilogramas de lâminas foliares por $100 \mathrm{~kg}$ de peso vivo por dia); e de outubro de 2002 a maio de 2003, outubro de 2003 a junho 
de 2004 e novembro de 2004 a junho de 2005 , as ofertas planejadas foram de 4, 8, 12 e $16 \%$ do peso vivo. As ofertas efetivas, no entanto, não foram iguais às planejadas e variaram de 2,9 a $15,3 \%$ do peso vivo (Tabela 1). As duas repetições ocuparam áreas de 1,5, 1,7, 2,5 e 3 ha, para as ofertas de 4, 8, 12 e $16 \%$ do peso vivo, respectivamente. Foram aplicados, por ano, $150 \mathrm{~kg} \mathrm{ha}^{-1}$ de N, parcelado em três aplicações de $50 \mathrm{~kg} \mathrm{ha}^{-1}$, em outubro, dezembro e fevereiro. Em 2004/2005, foram aplicados somente $100 \mathrm{~kg} \mathrm{ha}^{-1} \mathrm{de} \mathrm{N}$,

Tabela 1. Ofertas planejadas e efetivas (quilogramas de lâminas foliares por $100 \mathrm{~kg}$ de peso vivo por dia), em cada ano e repetição, em pastagem de Bachiaria brizantha, cultivar Marandu, submetida a ofertas de laminas foliares, obtidas nos períodos de outubro de 2002 a maio de 2003, outubro de 2003 a junho de 2004 e novembro de 2004 a junho de 2005.

\begin{tabular}{|c|c|c|c|c|c|c|}
\hline \multirow[t]{3}{*}{ Ofertas planejadas } & \multicolumn{6}{|c|}{ Ofertas efetivas } \\
\hline & \multicolumn{2}{|c|}{$2002 / 2003$} & \multicolumn{2}{|c|}{$2003 / 2004$} & \multicolumn{2}{|c|}{$2004 / 2005$} \\
\hline & $\mathrm{I}$ & II & I & II & $\mathrm{I}$ & II \\
\hline 4 & 4,1 & 5,8 & 3,1 & 3,3 & 3,1 & 2,9 \\
\hline 8 & 8,7 & 10,7 & 6,3 & 6,6 & 5,0 & 7,1 \\
\hline 12 & 12,1 & 13,6 & 8,2 & 9,3 & 8,3 & 8,6 \\
\hline 16 & 15,3 & 13,6 & 11,9 & 13,2 & 11,5 & 12,6 \\
\hline
\end{tabular}

pois em fevereiro de 2005 ocorreu deficit hídrico (Figura 1).

No pastejo foram utilizados bovinos machos, meio-sangue, resultantes do cruzamento das raças Nelore e Charolês. Na primeira estação seca, entre a desmama e o início do experimento, os animais permaneceram em pastagem de capim-marandu suplementados com sal proteinado. Foram castrados aos 13 meses e permaneceram no experimento dos 15 aos 23 meses de idade, durante as fases de recria e engorda.

O método de pastejo utilizado foi o de lotação contínua, ajustada mensalmente de acordo com a disponibilidade de lâminas foliares, pela técnica "put-and-take" (Mott \& Lucas, 1952). Em cada unidade experimental, havia quatro animais traçadores e um número variável de animais reguladores, pesados a cada 28 dias, sob jejum de 14 horas.

A massa de lâminas foliares foi estimada, a cada 28 dias, pelo método de rendimento comparativo (Haydock \& Shaw, 1975). Utilizaram-se três padrões de comparação, com disponibilidades baixa, média e alta. Com base nos padrões, foram realizadas de 32 a 42 leituras visuais, conforme o tamanho da unidade experimental. As leituras foram realizadas por três

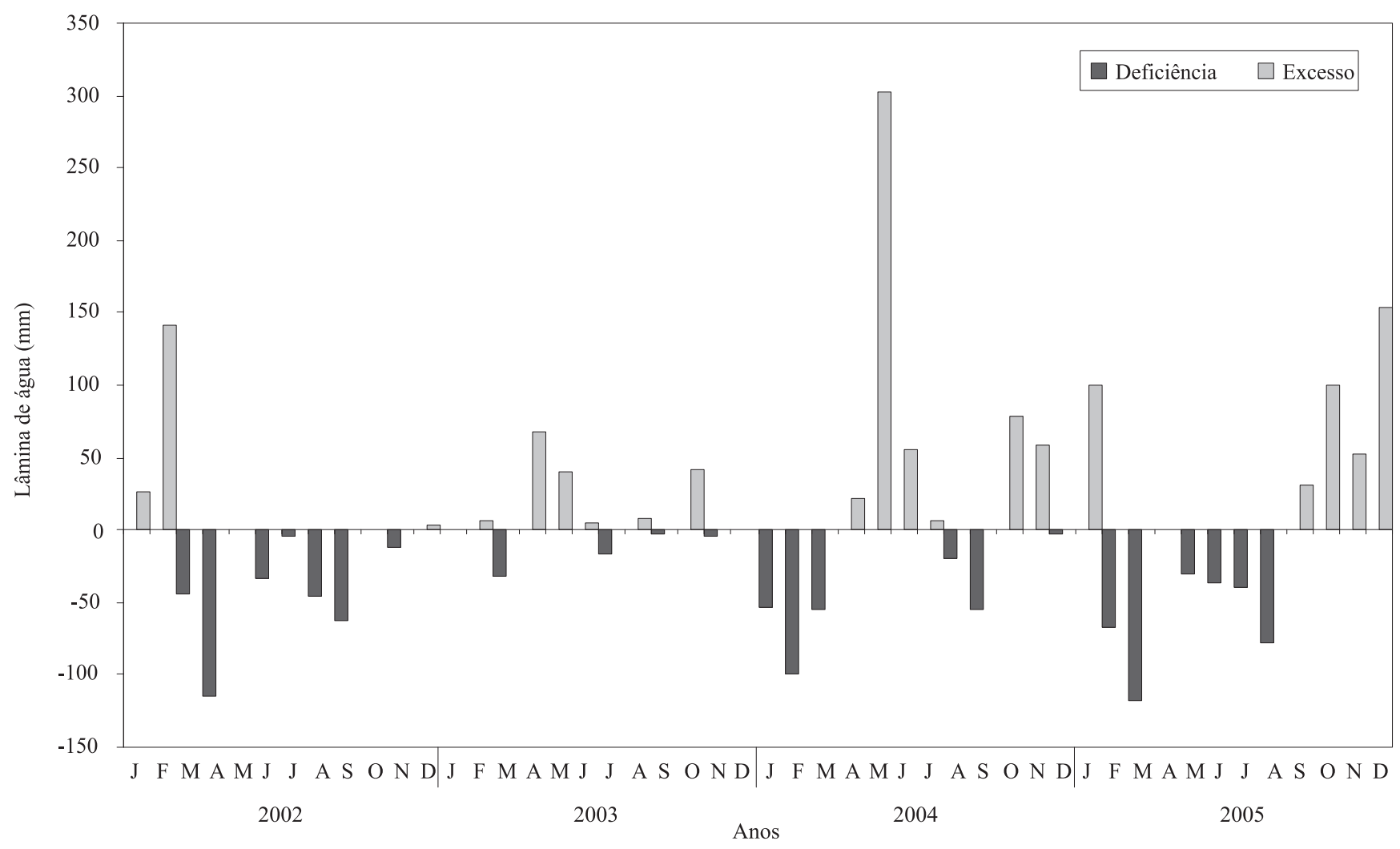

Figura 1. Balanço hídrico seqüencial de 2002 a 2005 em Dourados, MS. 
avaliadores, sempre nos mesmos pontos, distribuídos ao longo de dois transectos por unidade experimental.

Próximo aos transectos, foram colhidas quatro amostras aleatórias por unidade experimental. Numa área de $0,5 \times 1 \mathrm{~m}$, as amostras de forragem foram cortadas rente ao solo, com podador de cerca-viva. As amostras foram separadas nas frações lâmina foliar, colmo, bainha foliar, material morto e outras espécies presentes na pastagem. O material foi secado a $61^{\circ} \mathrm{C}$, em estufa com circulação forçada de ar, por 72 horas, para determinação da matéria seca. As curvas de calibração foram construídas entre a massa de lâminas foliares e as notas atribuídas pelos avaliadores $(n=48)$. A massa de lâminas foliares média, de cada unidade experimental, foi estimada pela equação de regressão, com a nota média obtida nos pontos dos transectos.

A taxa de acúmulo de lâminas foliares foi avaliada pela técnica da dupla amostragem. Duas áreas com massa e densidade de lâminas foliares, altura, coloração e intensidade de pastejo aparentemente semelhantes foram escolhidas e demarcadas. Uma das áreas foi delimitada com um retângulo de $0,5 \times 1 \mathrm{~m}$, e as plantas foram cortadas rente ao solo e, a outra área foi excluída do pastejo por gaiola de exclusão de tela de $1 \mathrm{~m}^{3}$, por um período de 28 dias. Após este período, as plantas contidas na gaiola de $0,5 \times 1 \mathrm{~m}$ foram cortadas no nível do solo. Os procedimentos de separação e secagem das amostras foram os mesmos utilizados para a massa de lâminas foliares. A taxa de acúmulo foi obtida pela diferença entre a massa de lâminas colhida na gaiola e a massa de lâminas colhida no mês anterior, na área adjacente à da gaiola, dividido pelo número de dias correspondente ao tempo de exclusão da área.

A altura do dossel foi determinada a cada 28 dias, nos mesmos pontos das determinações visuais de massa de lâminas foliares. Sobre o dossel, foi disposta uma prancheta de $0,2 \times 0,3 \mathrm{~m}$ de lado, que causou a pressão de $3,6 \mathrm{~kg} \mathrm{~m}^{-2}$ sobre as plantas, e a altura do dossel foi determinada com auxílio de régua.

Para determinação da matéria seca de raízes, foram abertas três trincheiras por unidade experimental, em maio de 2003, 2004 e 2005. Foram coletadas amostras de solo de $6 \times 40 \mathrm{~cm}$, nas profundidades de $0-5,5-10,10-20 \mathrm{e} 20-40 \mathrm{~cm}$. O solo foi destorroado, e as raízes foram colhidas manualmente com auxílio de pinças. Posteriormente, as raízes foram lavadas e secadas em estufa a $61{ }^{\circ} \mathrm{C}$, por 72 horas, para determinação da matéria seca.

$\mathrm{O}$ ajuste da taxa de lotação foi efetuado com base na estimativa da massa de lâminas foliares, em quilogramas por hectare, dividida por 28 dias, somada à taxa de acúmulo de lâminas foliares, em quilogramas por hectare por dia, tomada no período anterior, a qual foi projetada para o período seguinte. O produto desta soma foi multiplicado por cem e dividido pela oferta pretendida, em porcentagem, e com isto foi obtida a taxa de lotação, em quilogramas de peso vivo por hectare.

Para a análise estatística, foram utilizadas as médias de cada variável. Cada ponto nos gráficos equivale à média da unidade experimental e do ano, considerandose os pontos de amostragem em cada unidade e os meses avaliados, respectivamente. Os dados foram submetidos ao teste $\mathrm{F}$, e análises de regressão foram realizadas, tendo como variável independente as ofertas de lâminas foliares. As análises foram realizadas com auxílio do programa SigmaPlot 8.0 (Systat, 2002).

\section{Resultados e Discussão}

As ofertas de lâminas foliares pretendidas foram 4, 8, 12 e $16 \%$, mas como a taxa de lotação foi estipulada a priori, com base na projeção da taxa de acúmulo de lâminas, os valores médios de oferta corrigidos foram 3,7, $7,4,10$ e 13\%. Houve diminuição das ofertas (Tabela 1), provavelmente em conseqüência do deficit hídrico ocorrido nos dois últimos anos do estudo (Figura 1), o que afetou a produção de forragem.

A massa de lâminas foliares apresentou aumento linear significativo $(\mathrm{p}<0,001)$ com o aumento das ofertas (Figura 2). Respostas semelhantes foram obtidas por Almeida et al. (2000a), Gomide et al. (2001) e Barbosa et al. (2006), com capim-elefante (Pennisetum purpureum), braquiária (Brachiaria decumbens) e capim-tanzânia (Panicum maximum), respectivamente.

As ofertas de lâminas foliares, que permitiram os maiores ganhos por animal com capim-marandu, situaram-se entre 7 e $10 \%$ do peso vivo, valores esses que estimados pela equação $\mathrm{y}=660,6+142,7 \mathrm{x}$ corresponderam à massa de lâminas foliares de $1.660 \mathrm{a}$ $2.088 \mathrm{~kg} \mathrm{ha}^{-1}$ (Figura 2). Molan (2004) observou uma altura de dossel forrageiro entre 20 e $30 \mathrm{~cm}$, correspondentes à massa de lâminas de 2.052 a $2.833 \mathrm{~kg} \mathrm{ha}^{-1}$, respectivamente. Estes valores estão próximos aos obtidos no presente trabalho, mas são superiores aos obtidos por Euclides \& Euclides Filho (2001), que não observaram acréscimos no desempenho animal com massa de forragem acima de $1.000 \mathrm{~kg} \mathrm{ha}^{-1}$, considerando-se a fração verde da planta.

Com capim-elefante anão 'Mott', em regime de lotação contínua, Almeida et al. (2000a) observaram desempenho animal máximo nas ofertas de 10 e $11 \%$ do peso vivo, que equivalem às massas foliares de $2.000 \mathrm{a}$ $2.300 \mathrm{~kg} \mathrm{ha}^{-1}$. 
Em relação ao capim-tanzânia em lotação rotacionada, Martha Júnior et al. (2004) recomendaram um resíduo de 1.650 a $2.700 \mathrm{~kg} \mathrm{ha}^{-1}$ de matéria seca de tecido verde de forragem. Por sua vez, Barbosa et al. (2002) não observaram diferença no potencial produtivo entre as massas de forragem de 2.600 e $3.600 \mathrm{~kg} \mathrm{ha}^{-1}$ no póspastejo, para o capim-tanzânia. Para a cultivar Mombaça sob lotação rotacionada, Carnevalli (2003) observou maior eficiência de produção e colheita de forragem, no tratamento com início de pastejo com $95 \%$ de interceptação luminosa pelo dossel e $30 \mathrm{~cm}$ de altura de resíduo. Neste tratamento, a massa de forragem no prépastejo variou de 4.300 a $4.800 \mathrm{~kg} \mathrm{ha}^{-1}$ e, no pós-pastejo, de 1.470 a $2.010 \mathrm{~kg} \mathrm{ha}^{-1}$, conforme a época do ano.

A taxa de acúmulo de lâminas, em consequiência da oferta, não apresentou significância (Figura 2), fato que pode ser atribuído às ofertas utilizadas neste trabalho e a outros fatores, tais como o método utilizado, disponibilidade de água e variações espaciais. Por sua vez, o número de pontos amostrados, quatro por unidade experimental, a cada 28 dias, pode ter sido insuficiente para a variação existente na área experimental. Houve uma limitação ao aumento do número de pontos, em razão das dificuldades relacionadas ao tempo de amostragem, número de amostradores e ao alto custo das gaiolas de exclusão. Para a prática agronômica de avaliação da taxa de acúmulo, é assumido que a área de pastagem fique 28 dias sem pastejo, o que nem sempre ocorre. Gonçalves (2002) ao avaliar o capim-marandu sob lotação contínua, observou decréscimo significativo da freqüência de desfolha, com o aumento da altura do dossel forrageiro. Nesse estudo, a freqüência de desfolha variou, em média, de 0,077 a 0,058 desfolhações por perfilho por dia, correspondente a descansos de 13 a 17 dias, para as alturas do dossel de 10 e $40 \mathrm{~cm}$, respectivamente. Portanto, o uso de gaiolas pode ter contribuído para a superestimativa da taxa de acúmulo, nas áreas com as menores ofertas, uma vez que os pontos amostrados ficavam protegidos do pastejo por 28 dias.

Em pastagens de capim-marandu, no período de janeiro a dezembro de 2002, Molan (2004) observou menor taxa de acúmulo de forragem, na altura do dossel forrageiro de $40 \mathrm{~cm}$, em relação a 10, 20 e $30 \mathrm{~cm}$, não tendo observado diferença nas menores alturas. No período de novembro de 2001 a fevereiro de 2002, Lupinacci (2002) observou maior taxa de acúmulo de forragem nas alturas de dossel de 20 e $30 \mathrm{~cm}$, em relação a $10 \mathrm{~cm}$. Em lotação rotacionada, Braga et al. (2006) avaliaram seis ciclos de pastejo e observaram resposta linear da taxa de acúmulo às ofertas de forragem, somente nos dois primeiros ciclos. Com a mesma espécie de capim, submetido às ofertas diárias de 3,5 e $7 \mathrm{~kg}$ da folhas verdes por $100 \mathrm{~kg}$ de peso vivo, em lotação rotacionada, Garay et al. (2002) observaram maior taxa de acúmulo de lâminas foliares no menor nível, em relação ao maior.

$\mathrm{Na}$ avaliação da taxa de crescimento de folhas de capim-marandu, pelo método de fluxo de tecidos, Sbrissia (2004) observou valores mais elevados, quando a pastagem foi mantida com uma altura média de $30 \mathrm{~cm}$,

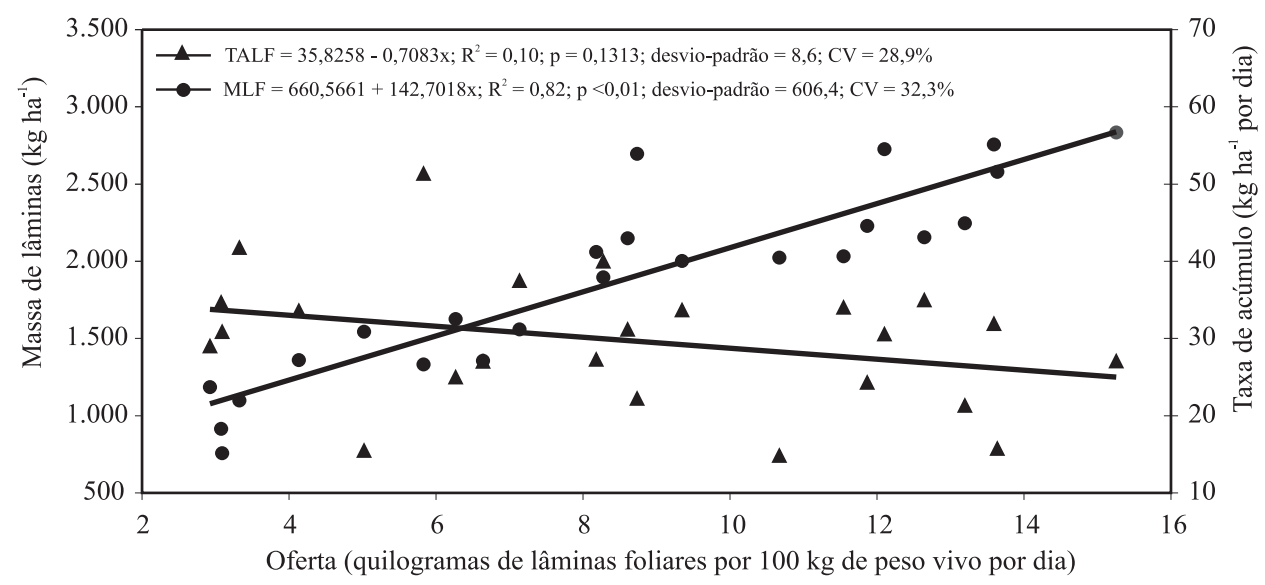

Figura 2. Massa de lâminas foliares (MLF) e taxa de acúmulo de lâminas foliares (TALF), em pastagem de Brachiaria brizantha, cultivar Marandu, submetida a ofertas de lâminas foliares, obtidas nos períodos de outubro de 2002 a maio de 2003, outubro de 2003 a junho de 2004 e novembro de 2004 a junho de 2005. 
em relação a 10, 20 ou $40 \mathrm{~cm}$. Almeida et al. (2000a) verificaram aumento na taxa de acúmulo para o capim-elefante anão 'Mott', pelo método agronômico, com o aumento de oferta de folhas de 4 a $10 \%$ do peso vivo. Canto et al. (2001) não observaram relação entre a taxa de acúmulo e a altura da pastagem de capim-tanzânia.

A matéria seca de raízes apresentou grande variação entre as unidades experimentais, tendo resultado em coeficiente de determinação baixo (Figura 3). Assim como a taxa de acúmulo, esta variável pode estar relacionada a outros fatores e não somente à oferta de lâminas. Em razão da dificuldade na medição da matéria seca de raízes, foram avaliados apenas três pontos por unidade experimental por ano. Em pastagens de capim-marandu, submetidas às alturas de dossel de 10, 20, 30 e 40 cm, Lupinacci (2002) não observou diferença na matéria seca de raízes. Entretanto, Almeida et al. (2000a) observaram que o aumento da massa radicular foi proporcional ao aumento da oferta de lâminas, em pastagem de capim-elefante anão cultivar Mott.

O manejo do capim-marandu, com diferentes ofertas de lâminas foliares, modificou a estrutura do dossel. Para a altura do dossel, a regressão foi significativa $(p<0,01)$, com aumento linear das ofertas (Figura 4). A altura estimada do dossel foi, em média, de 8, 17,3, 23,9 e $31,5 \mathrm{~cm}$, para as ofertas médias 3,7, 7,4,10,02 e 13\% do peso vivo, respectivamente. Resposta linear de altura do dossel à oferta de lâminas em lotação contínua também foi obtida em pastagens de capim-elefante anão cultivar Mott por Almeida et al. (2000a). Barbosa et al. (2006) obtiveram relação quadrática entre altura do capim-tanzânia e ofertas de forragem.

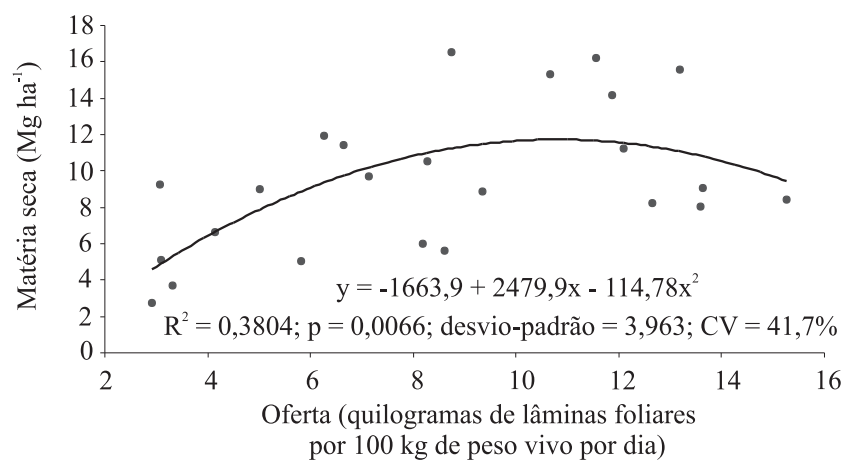

Figura 3. Matéria seca de raízes colhidas em maio de 2003, 2004 e 2005, em pastagem de Brachiaria brizantha, cultivar Marandu, submetida a ofertas de lâminas foliares.

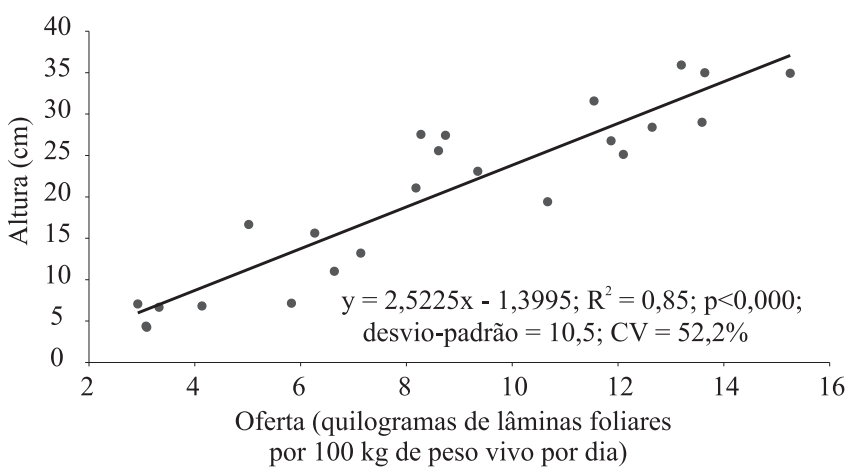

Figura 4. Altura do dossel em pastagem de Brachiaria brizantha, cultivar Marandu, submetida a ofertas de lâminas foliares, durante os períodos de outubro de 2002 a maio de 2003, outubro de 2003 a junho de 2004 e novembro de 2004 a junho de 2005.

\section{Conclusão}

Em pastagem de Brachiaria brizantha cultivar Marandu, a massa de lâminas foliares e a altura do dossel aumentam linearmente com o aumento da oferta de lâminas foliares.

\section{Agradecimentos}

Ao Sr. Nestor Ivo Bocchi, pelo fornecimento dos animais; ao Médico Veterinário Elton Bock Correa, pela colaboração; ao CNPq, pela bolsa concedida.

\section{Referências}

ALMEIDA, E.X. de; MARASCHIN, G.E.; HARTHMANN, O.E.L.; RIBEIRO FILHO, H.M.N.; SETELICH, E.A. Oferta de forragem de capim-elefante anão 'Mott' e a dinâmica da pastagem. Revista Brasileira de Zootecnia, v.29, p.1281-1287, 2000a.

ALMEIDA, E.X. de; MARASCHIN, GE.; HARTHMANN, O.E.L.; RIBEIRO FILHO, H.M.N.; SETELICH, E.A. Oferta de forragem de capim-elefante anão 'Mott' e o rendimento animal. Revista Brasileira de Zootecnia, v.29, p.1288-1295, 2000 b.

BARBOSA, M.A.A. de F.; NASCIMENTO JÚNIOR, D. do; CECATO, U. Dinâmica da pastagem e desempenho de novilhos em pastagem de capim-tanzânia sob diferentes ofertas de forragem. Revista Brasileira de Zootecnia, v.35, p.1594-1600, 2006.

BARBOSA, R.A. Características morfofisiológicas e acúmulo de forragem em capim-tanzânia (Panicum maximum Jacq. cv. Tanzânia) submetido a freqüências e intensidades de pastejo. 2004. 119p. Tese (Doutorado) - Universidade Federal de Viçosa, Viçosa.

BARBOSA, R.A.; NASCIMENTO JÚNIOR, D. do; EUCLIDES, V.P.B.; REGAZZI, A.J.; FONSECA, D.M. Características 
morfogenéticas e acúmulo de forragem do capim-tanzânia (Panicum maximum Jacq. cv. Tanzânia) em dois resíduos forrageiros póspastejo. Revista Brasileira de Zootecnia, v.31, p.583-593, 2002.

BARCELLOS, A.O. Sistemas extensivos e semi-intensivos de produção bovina de corte nos Cerrados. In: SIMPÓSIO SOBRE O CERRADO, 8.; INTERNACIONAL SYMPOSIUM ON TROPICAL SAVANNA, 1., 1996, Brasília. Anais. Planaltina: Embrapa-CPAC, 1996. p.130-136.

BRAGA, G.J.; PEDREIRA, C.G.S.; HERLING, V.R.; LUZ, P.H. de C.; LIMA, C.G. de. Sward structure and herbage yield of rotationally stocked pastures of 'Marandu' palisade grass (Brachiaria brizantha (A. Rich.) Stapf) as affected by herbage allowance. Scientia Agricola, v.63, p.121-129, 2006.

CANO, C.C.P.; CECATO, U.; CANTO, M.W. do; SANTOS, G.T. dos; GALDEIRO, S.; MARTINS, E.N.; MIRA, R.T. Valor nutritivo do capim-tanzânia (Panicum maximum Jacq. cv. Tanzânia-1) pastejado em diferentes alturas. Revista Brasileira de Zootecnia, v.33, p.1959-1968, 2004.

CANTO, M.W. do; CECATO, U.; PETERNELLI, M.; JOBIM, C.C.; ALMEIDA JÚNIOR, J.; RIGOLON, L.P.; WATFE, E.; BARRIONUEVO, C.V.; NUNES, B.R.C. Efeito da altura do capim-tanzânia diferido nas características da pastagem no período de inverno. Revista Brasileira de Zootecnia, v.30, p.1186-1193, 2001.

CARNEVALLI, R.A. Dinâmica da rebrotação de pastos de capimmombaça submetidos a regimes de desfolhação intermitente. 2003. 136p. Tese (Doutorado) - Universidade de São Paulo, Piracicaba.

COSTA, F.P. Pecuária de corte no Brasil Central: o produtor, os recursos produtivos e o manejo das pastagens. Campo Grande: Embrapa Gado de Corte, 2000. (Embrapa Gado de Corte, Circular Técnica, 26) Disponível em: http://www.cnpgc.embrapa.br/ publicacoes/ct/ct26. Acesso em: 30 ago. 2007.

EMBRAPA. Embrapa Gado de Corte. Marandu: cultivar de Brachiaria brizantha. Campo Grande: Embrapa Gado de Corte, 2007. 2p. Disponível em: http://www.cnpgc.embrapa.br/ produtoseservicos/pdf/marandu.pdf. Acesso em: 30 jul. 2007.

EUCLIDES, V.P.B.; EUCLIDES FILHO, K. Produção de carne em pastagens. In: SIMPÓSIO SOBRE MANEJO DA PASTAGEM, 18., 2001, Piracicaba. Anais. Piracicaba: Fealq, 2001 p. 321-351.

FORBES, T.D.A.; HODGSON, J. Comparative studies of the influence of sward conditions on the ingestive behaviour of cows and sheep. Grass and Forage Science, v.40, p.69-77, 1985.

GARAY, A.H.; HERNÁNDEZ, P.A.M.; MARTÍN, M.U.; PÉREZ, J.P.; JAVIER, F.E.Q. Dinámica del rebrote en pasto insurgente (Brachiaria brizantha (Hochst.) Stapf.) pastoreado a diferente asignación en la estación de lluvias. Técnica Pecuaria en México, v.40, p.193-205, 2002.

GOMIDE, J.A.; WENDLING, I.J.; BRAS, S.P.; QUADROS, H.B. Consumo e produção de leite de vacas mestiças em pastagem de Brachiaria decumbens manejada sob duas ofertas diárias de forragem. Revista Brasileira de Zootecnia, v.30, p.1194-1199, 2001.

GONÇALVES, A. de C. Características morfogênicas e padrões de desfolhação em pastos de capim-marandu submetidos a regimes de lotação contínua. 2002. 124p. Dissertação (Mestrado) - Universidade de São Paulo, Piracicaba.

HAYDOCK, K.P.; SHAW, N.H. The comparative yield method for estimating dry matter yield of pasture. Australian Journal of Experimental Agriculture and Animal Husbandry, v.15, p.663670, 1975.

HODGSON, J. Sward conditions, herbage allowance and animal production: in evaluation of research results. Proceedings of New Zealand Society of Animal Production, v.44, p.99-104, 1984.

LUPINACCI, A.V. Reservas orgânicas, índice de área foliar e produção de forragem em Brachiaria brizantha cv. Marandu submetida a intensidades de pastejo por bovinos de corte. 2002. 160p. Dissertação (Mestrado) - Universidade de São Paulo, Piracicaba.

MACHADO, L.A.M.; KICHEL, A.N. Ajuste de lotação no manejo de pastagens. Dourados: Embrapa Agropecuária Oeste, 2004. 55p. (Embrapa Agropecuária Oeste. Documentos, 62). Disponível em: http://www.cpao.embrapa.br/publicacoes. Acesso em: 11 ago. 2006.

MARASCHIN, G.E.; MOTT, G.O. Resposta de uma complexa mistura de pastagem subtropical a diferentes sistemas de pastejo. Pesquisa Agropecuária Brasileira, v.24, p.221-227, 1989.

MARTHA JÚNIOR, G.B.; CORSI, M.; BARIONI, L.G.; VILELA, L. Intensidade de desfolha e produção de forragem do capim-tanzânia irrigado na primavera e no verão. Pesquisa Agropecuária Brasileira, v.39, p.927-936, 2004.

MOLAN, L.K. Estrutura do dossel, interceptação luminosa e acúmulo de forragem em pastos de capim-marandu submetidos a alturas de pastejo por meio de lotação contínua. 2004. 179p. Dissertação (Mestrado) - Universidade de São Paulo, Piracicaba.

MOTT, G.O.; LUCAS, H.L. The design, conduct and interpretation of grazing trials in cultivated and improved pastures. In: INTERNATIONAL GRASSLAND CONGRESS, 6., 1952, Pasadena. Proceedings. Pasadena: Pensylvannia State College, 1952. p.1380-1385.

MULLER, M.M.L.; GUIMARAES, M. de F.; DESJARDINS, T.; MARTINS, P.F. da S. Degradação de pastagens na Região Amazônica: propriedades físicas do solo e crescimento de raízes. Pesquisa Agropecuária Brasileira, v.36, p.1409-1418, 2001.

PERON, J.A.; EVANGELISTA, A.R. Degradação de pastagens em regiões de cerrado. Ciência e Agrotecnologia, v.28, p.655-661, 2004.

SBRISSIA, A.F. Morfogênese, dinâmica do perfilhamento e do acúmulo de forragem em pastos de capim-marandu sob lotação contínua. 2004. 198p. Tese (Doutorado) - Universidade de São Paulo, Piracicaba.

SOLLENBERGER, L.E.; MOORE, J.E.; ALLEN, V.G.; PEDREIRA, C.G.S. Reporting forage allowance in grazing experiments. Crop Science, v.45, p.896-900, 2005.

SYSTAT. Sigmaplot. Chicago: Systat Software Inc., 2002. (Version 8.02).

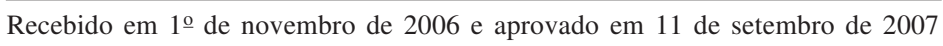

